\title{
Interactive Whiteboard and Instant Quiz for Multimedia Classroom Activity
}

\author{
Ary Mazharuddin Shiddiqi ${ }^{1}$, Royyana M. Ijtihadie ${ }^{1}$, Emerson Eridiansyah Z ${ }^{1}$, Baskoro A. Pratomo ${ }^{1}$, \\ Tohari Ahmad ${ }^{1}$, and Waskhito Wibisono ${ }^{1}$
}

\begin{abstract}
Information and communication technology have become a very strategic aspect in supporting human life. One of the aspects is in education, particularly the use of e-learning system. In the e-learning system, the use of multimedia (such as video conferencing) technology allows users to have an interactive meeting without having to see collocutor directly. In this system, each user communicates by using computer networks, either locally or through the internet. This trend has encouraged developers to create such applications online. However, most of them are paid application and less convenient to use. This research developed an interactive e-learning system with features such as online quiz, whiteboard, video conference and VoIP. In this system, a web based e-learning system with video VoIP provides learning activities by the interaction of both parties that lecturers and students. This system enables the teacher and user to have an interactive conversation and to have quizzes in the middle of a class. This method is aimed to evaluate the students understanding of the materials currently presented. Delay and jitter value of this system increases along with the increase number of users. With the 15 users, the Hypertext Transfer Protocol (HTTP) delay value reaching 32.3672 and $101.6028 \mathrm{~ms}$ for the jitter value. Furthermore with 15 users, the Real Time Messaging Protocol (RTMPO delay value reached $51.8868 \mathrm{~ms}$ and $92.0052 \mathrm{~ms}$ for the jitter value.
\end{abstract}

Keywords - multimedia, classroom, interactive whiteboard, video conference.

\section{INTRODUCTION}

$\mathrm{N}$ owadays, technology has changed the way of teaching. In the past, typical traditional classroom would be a class provided with combination of either a blackboard-chalk or whiteboard-marker. Recently, it is common for teacher to use a multimedia slides with all those advantages to deliver a course material in a classroom.

Moreover, there is a model of classroom which is equipped with computer entirely to accommodate the requirement of practical action during the class activity, such as programming courses session or network configuration course session. Laboratory activities are major parts in information and communication technology courses. Such could help learners to a better comprehension and while also providing them problemsolving skills and experience necessary in real-life contexts $[1,2]$.

In the recent years, the usage of Interactive White Board (IWB) technology is believed to be able to constitute an effective and convenient way to deliver the learning content while also improving learner's learning experience $[3,4]$

In some extent, an instant response from the student during the course is necessary for the teacher to build up a decision regarding further class activity for a particular material. In addition, responses from student could be employed by the teacher to decide the pace of the material delivery.

For example, with such type of multimedia classroom, the teacher may give sudden instant quizzes to either a particular student or group of student to collect responses regarding their comprehension to the current teaching

${ }^{1}$ Ary Mazharuddin Shiddiqi, Royyana M. Ijtihadie, Emerson Eridiansyah Z, Baskoro A. Pratomo, Tohari Ahmad, and Waskhito Wibisono are with Departement of Informatics Engineering, Faculty of Information Technology, Institut Teknologi Sepuluh Nopember, Surabaya, 60111, Indonesia. E-mail: ary.shiddiqi@cs.its.ac.id. topic. The quizzes might be an interactive whiteboard or a series of questions.

This paper discusses an infrastructure of interactive whiteboard and instant quiz activity for multimedia classroom with multimedia technology.

The organization of this paper is as follows. Some related works are presented in section 2. Section 3 describes literature studies of several tools employed to build this system. Section 6 discusses the evaluation of the system and we conclude this paper in Section 7.

\section{RELATED WORKS}

There have been several works to deal with a provision of interactive whiteboards as follows:

Interactive response system (IRS) [5] provides an interactive instructional system by providing remote controls for each of participants. It also provides the capability to carry out a spontaneous quiz during the lecture on the shared display. On the contrary, our system provides a personal spontaneous quiz session to measure student comprehension about topic in which the teacher may ask unique quiz among the students.

Interactive Electronic Whiteboard $[6,7]$ works in the similar way with the previous while our system provides a video conference screen allowing the teacher to speak personally with a particular student. An example of class management over internet using RTMP protocol has been implemented by Premchaiswadi et. A. that uses TCP-protocol to increase efficiency of message exchange, data synchronization for audio and video [8].

\section{RESULT AND DISCUSSION}

This section contains the literatures used to construct the idea of research and implement the system. The details of the components are presented in the next subchapters.

\section{A. Video Conference and Voice over Internet}

Video conferencing technology was firstly introduced by AT\&T in 1970 through the application named Picturephone. Video conferencing is now frequently 
used include Skype, MSN Messenger and Yahoo Messenger. In this technology, the type of video conferencing can be divided into three models, namely personal video conferencing, video conferencing and business video conferencing web.

Personal video conferencing is also called video call. Business video conferencing is a conferencing service designed specifically to meet the business needs with the features such as the ability to invite people in the audio and video calls, collaboration, document sharing, and presentations. Web video conferencing is conferencing service designed to perform audio and video communication via web pages.

Voice over Internet Protocol (VoIP) is a technology that allows voice communication via the Internet. The voice data is converted from analog to digital code. Then the data is transmitted over the network to transmit data packets. The advantage of VoIP technology is to minimize the cost of communication. VoIP Network Architecture uses the Internet Protocol for providing voice communications in real-time manner.

\section{B. Real Time Messaging Protocol}

Real Time Messaging Protocol (RTMP) [9] was a protocol initially developed by Macromedia used for streaming audio, video and data over the internet. RealTime Messaging Protocol (RTMP) differs from HTTP in its functionality. Real Time Messaging Protocol (RTMP) is aimed at the development of applications such as realtime chat and streaming video applications, while HTTP is mainly used for web page applications $[10,11]$.

\section{Red5 Flash Media Server}

Red5 [12] is an open-source server developed in Java environment, used in integration with Adobe Flash Player. Red5 has the ability to stream audio and video, broadcast live in real-time, shared object, and client recorded streams. Red5 is suitable framework for Flash application platform.

\section{FreeSWITCH and BigBlueButton}

FreeSWITCH [13] is a cross-platform software designed to communicate using audio, video, text or any other media. This software was created in 2006. FreeSWITCH also provides a stable phone platform in which many telephony applications developed. BigBlueButton [14] is an open source video conferencing system that enables universities to provide a learning infrastructure to students in solitary areas. BigBlueButton supports document sharing, video conferencing, chatting and voice call. The system can also be developed using various other open-source components. Most of FreeSWITCH and BigBlueButton facilities are employed in this system. There are several essential Appication Programming Interfaces (API) of the BigBlueButton framework that are used in this research, they are:

1) createMeeting, used to start a video conferencing. There are several parameters in this function, i.e. lecture and lectured id. These parameters are used to identify aunique video conferencing should a user is joining.

2) endMeeting, this function it is used in contrast with the createMeeting function. This method is used to end a video conferencing session. The endMeeting uses similar parameters with ones used in createMeeting method.

3) getJoinMeetingUrlAttendee, used to join a video conference by students who will act as an attendee. Parameters used are session contents which stores student's username that will be displayed as the indentification of the attendee at the video conference.

4) getJoinMeetingUrlModerator, used to join a video conferencing by lecturers who will act as moderator. Parameters used are session contents which stores a lecturer username that will be displayed as the identification of the attendee at the video conference.

\section{SYSTEM ARCHITECTURE}

This section discusses analysis, design, and implementation of Interactive with web-based video conferencing VoIP learning systems using RTMP protocol.

\section{A. General Description}

This research developed a system used as an education media via intranet to be a support tool in multimedia classroom. This system uses client-server architecture. ELearning system server responsible for user management and administrator conducted by teacher. The students will be able to participate in the video conference conducted by teacher. In addition, the teacher may sometime carry out an instant quiz to particular group of student. Figure 1 shows the general description of the system.

Each class is managed separately, thus the teacher has a full authority. The teacher are able to enroll students, sets interactive quizzes, creating video conference and uploading files to whiteboard. The materials uploaded are then available for the student to access based on their enrollment. Figure 2 shows the class management. The figure shows that a class can be enrolled by students with similar features. In the experiment section, the maximum users allowed to join a class is observed to evaluate the capacity of the class with optimum Quality of Service.

1) System Features

This system has several functionalities performed by either administrator; lecturers or students such as add users, user enrollment, create and joining video conferences, etc.

2) Enrolling students

Lecturers or faculty staff can enroll any student in a class. Lecturers must $\log$ in to the system using username and password, then, select the menu to enroll students. At the menu, a student will be enrolled in classes that he/she registered.

3) Set The Interactive Quiz

The interactive quiz consists of a short multiple choice quiz and essay prepared by the lecturer. When a particular quiz is set, the students have to work on the quiz to observe the level of understanding of the material presented by the lecturer.

4) Participating in Video Conference

Each lecturer and students can join video conference system according to their rights. The lecturer acts as a moderator that organizes the conference, while the students act as attendees of a conference in which 
they can make the interaction of each other at the conference system.

5) Uploading Files to Whiteboard

Every lecturer who is acting as a moderator in a video conference is capable of uploading teaching materials and learning support tools such as image files, documents and power point slides. Once the files uploaded, the attendee of the class can access it.

6) Working on Interactive Quiz

Students can work on an interactive quiz that has been set by lecturers. As mentioned before, the quiz consists of interactive multiple choice or essays. The quiz is aimed to observe the level of student understanding of the learning material.

\section{WORKING EXAMPLE}

This research has implemented the interactive elearning system in Local Area Network with the environment explained in Table 1 and Table 2.

\section{A. User Management}

In this system, administrator acts as a user whose job is to control and supervise the system. So, an administrator can also perform user management to add new users to the system. In a user add form, username and password must be filled in, along with the type of user before registration takes place.

\section{B. Course User Admission}

User admission task can be done by lecturer and elearning administrator. However, this task is often performed by lecturers. The students are enrolled according to subjects that they have chosen. This task is performed by choosing the name of the student as well as courses taken, prior to enrolling the user to a class. Should there be needed to add a new subject, this menu also has a link to add subject form.

\section{Instant Quiz during the course}

Lecturer as teaching and learning guide sets up interactive multiple choice and essay quiz to determine the level of understanding of the course materials being given in a virtual classroom. Fig. 4 and Fig. 5 show the example of the instant quiz during the course session.

\section{Joining a Video Conferencing}

Each user can join a courses of video conference in accordance with their respective enrollment. When lecturers and students are about to join a video conference, their access right are set according to their privileges. This is done by the use of username and access rights attributes stored in web session.

\section{E. Uploading files to Whiteboard}

This function is assigned to lecturer that acts as moderator in a course. The file will be displayed on whiteboard as a mean to support the teaching and learning process.

\section{F. Working on Interactive Quiz}

In this system, an interactive quiz is developed attended by students presented in interactive multiple choice and essay quizzes. This quiz runs when the teacher is willing to test students in an on-going lecture. The quiz will take place when student pressed a button to initiate an interactive quiz.

\section{SYSTEM EVALUATION}

This experiment was conducted to evaluate whether the required functionalities work as it should do. There are three scenarios used to this need, they are: functional evaluation, system performance and user experience. The details of the evaluations are discussed in the next sections.

\section{A. Functional Evaluation}

This experiment is generally composed of two parts, namely the functional testing and performance testing. In order to perform this scenario, this research used several use cases that describes details of actions performed. An example of the use cases is shown in Table 3.

Table 4 shows the ID of each use case and its experiment ID that have been conducted. The result of the experiment shows that the functionality of the system has been implemented with successful result.

\section{B. Performance}

The system was also tested in terms of performance. The experiment was conducted by means of capturing packet between HTTP and RTMP protocol. The second protocol is the most dominant protocol in packet capturing. The experiment result is presented in Table 4 . The table shows that the delay depends on the number of users accessing the system simultaneously.

1) Delay

Three experiments were conducted using 5, 10 and 15 users. This experiment observed delay by the system. The delay is then classified into levels according to ITUT G.114 as described in Table 5. As the number of user increases, the delay also increases dramatically as seen in Figure 12. Experiment with 15 users is the number of users that can be performed smoothly in this environment. As seen in the figure, the delay increased significantly when the number of user increased from 10 to 15 users.

2) Jitter

The comparison of jitter categories are presented in Table 6 . The table shows categories for jitters produced in computer networks according to ITU-T G.823. A similar experiment scenario was conducted as in delay experiment with 5, 10 and 15 users.

As the number of users increases, the jitter value also grows. In the experiments with 5 users, jitter can still be categorized in good condition, as well as experiment with 10 users. However, if the number of users reaches 15 users, the jitter value moved to less good as the value of both HTTP and RTMP protocol increased significantly. These protocols are the most dominant among the other protocols.

Delay and jitter increase are aligned with the increase in the number of users. This experiment observed the maximum number of users that can be served with the current server. By using the similar scenario with the previous experiment, it was found that operation with 20 concurrent users is the maximum number for this system to run smoothly. 


\section{User Experience}

This research also observed questionnaires for users to assess the feasibility of this system from various aspects such as the ease of use of key features, display and layout colors as well as other supporting aspects. The assessment aspects use parameter numbers for stating the user opinion. This questionnaire is expected to obtain user's assessment as objective as possible.

From the questionnaire response (Table 7), users reflected that the current system is satisfying in terms of functionality and user interface. The ease of use of the system's features and whiteboard display quality are the topmost point in the assessment given by the user. In addition, the aspects of color appearance and layout as well as a whiteboard display quality aspects are the aspects that needed to be improved further.

Assessment criteria:

$$
\begin{aligned}
& 5=\text { Very Good } \\
& 4=\text { Good } \\
& 3=\text { Enough } \\
& 2=\text { Not Good } \\
& 1=\text { Bad }
\end{aligned}
$$

\section{CONCLUSION}

An application of instant quiz and interactive whiteboard for multimedia classroom is presented in this paper. This paper shows the application that user satisfied in the most assessed aspects. However, the performance is still low in the amount of delay and jitter which is something needs to be fixed in the future.

\section{ACKNOWLEDGEMENT}

The authors would like to thank Institut Teknologi Sepuluh Nopember and Directorate of Higher Education. This work is supported in part by a grant from a Lab Based Education Grant 2013.

\section{REFERENCES}

[1]. N.I. Sarkar, "Teaching Computer Networking Fundamentals Using Practical Laboratory Exercises," IEEE Trans. Education, vol. 49, no. 2, pp. 285-291, May 2006.

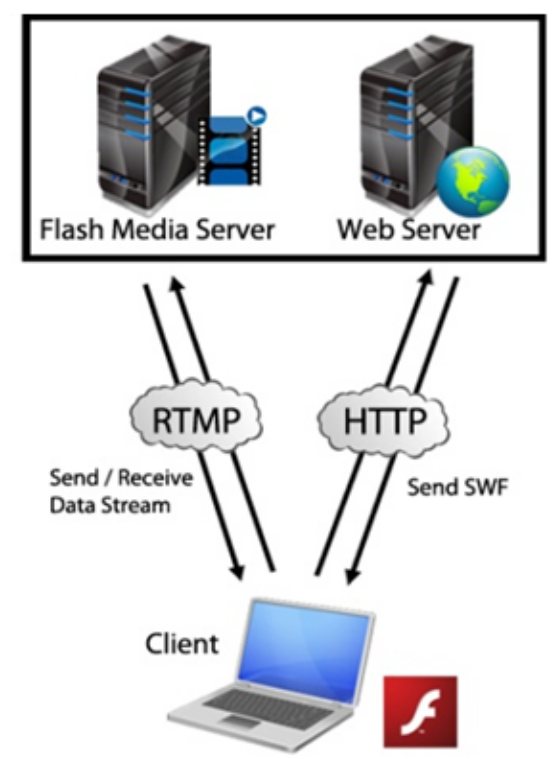

Students and teacher

Figure 1 System architecture
[2]. N. Linge and D. Parsons, "Problem-Based Learning as an Effective Tool for Teaching Computer Network Design," IEEE Trans. Education, vol. 49, no. 1, pp. 5-10, Feb. 2006.

[3]. Essam Bakadam, Mohammed J. Sharbib Asiri, Teachers' Perceptions Regarding the Benefits of using the Interactive Whiteboard (IWB): The Case of a Saudi Intermediate School, Procedia - Social and Behavioral Sciences, Volume 64, 9 November 2012, Pages 179-185, ISSN 1877-0428, http://dx.doi.org/10.1016/j.sbspro.2012.11.021.

[4]. Majid Zare Bidaki, Najmeh Mobasheri, Teachers' Views of the Effects of the Interactive White Board (IWB) on Teaching, Procedia - Social and Behavioral Sciences, Volume 83, 4 July 2013, Pages 140-144, ISSN 1877-0428, http://dx.doi.org/10.1016/j.sbspro.2013.06.027.

[5]. Huan-Ming Chuang, Chia-Cheng Shen, Li-Chuan Wang, "Using an Interactive Response System in Conjunction with Interactive Whiteboards Technology to Enhance Learning," 2013 International Conference on Computing, Networking and Communications (ICNC), pp. 657-661, 2008 Fourth International Conference on Natural Computation, 2008

[6]. Tao Hui-xian, Sun Ming, Cui Yan, Zhang Chun-e, "Application of Interactive Electronic Whiteboard System in Education," Information Technology and Computer Science, International Conference on, pp. 457-460, 2009 International Conference on Information Technology and Computer Science, 2009

[7]. Chao Li; Bellarmine, G.T.; Prosper, L., "Tablet PC as an innovative instructional technology in Electronic Engineering Technology (EET) course delivery (non-refereed)," Southeastcon, 2009. SOUTHEASTCON '09. IEEE, vol., no., pp.443,443, 5-8 March 2009

[8]. doi: 10.1109/SECON.2009.5174121

[9]. Anucha Tungkasthan, Phaisarn Sutheebanjard, and Wichian Premchaiswadi, "Classroom on the Internet using RTMP," in Engineering Education (EDUCON), 2010 IEEE, Bangkok, 2010, pp. From 1531 to 1537.

[10]. Adobe, "Real Time Messaging Protocol Specification", http://www.adobe.com/devnet/rtmp.html, accessed October, 2013.

[11]. Pujianto, "Development of Web-Based Video VoIP Phone Using RTMP protocol,", Surabaya, 2012, pp. 1-9.

[12]. I Dewa Made Wiana Institution, "Implementation of Web-Based VoIP Video Conference Using RTMP protocol," in National Seminar System and Informatika 2012, Bali, 2012, pp. 1-9.

[13]. Red5, “ The Open Source Media Server”, http://www.red5.org, accessed October, 2013

[14]. FreeSWITCH, multiprotocol softswitch, http://www.freeswitch.org, accessed October, 2013.

[15]. BigBlueButton, http://www.bigbluebutton.org, accessed October, 2013.
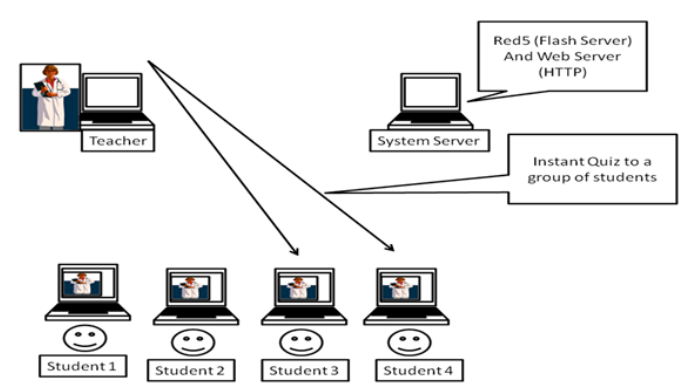

Figure 2 Class Management

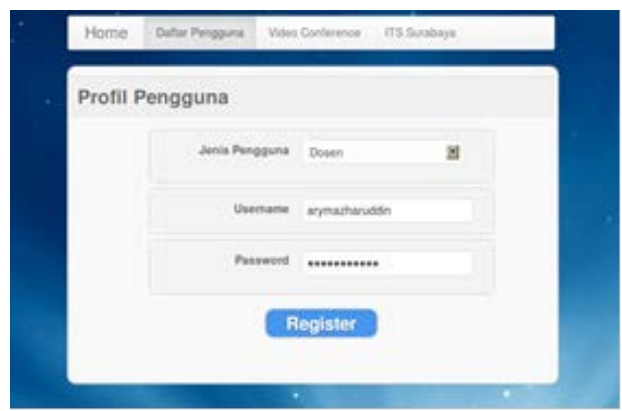

Figure 2. User Management Screen 


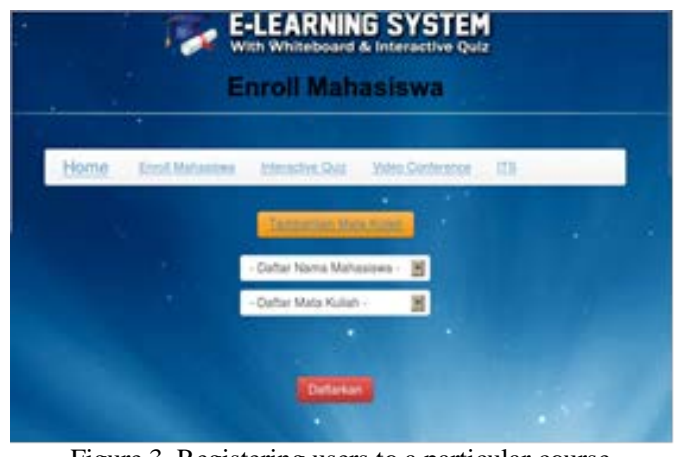

Figure 3. Registering users to a particular course

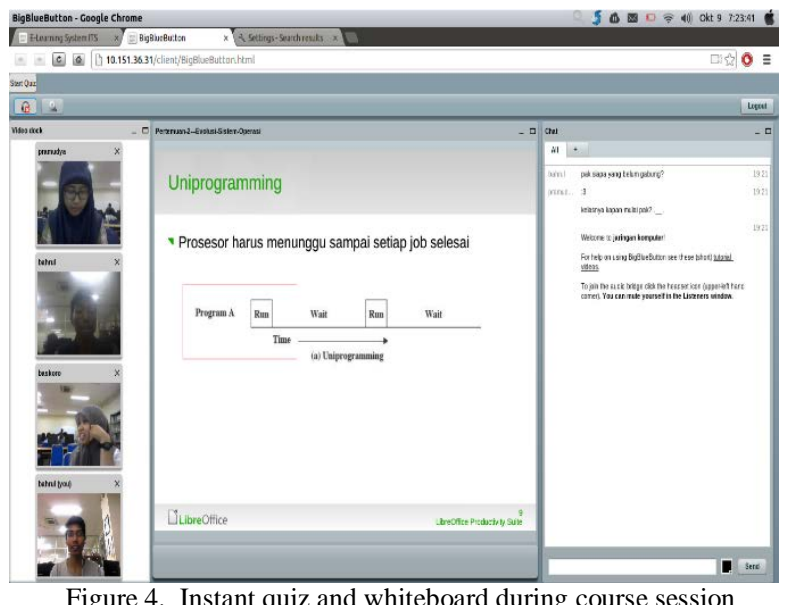

Figure 4. Instant quiz and whiteboard during course session
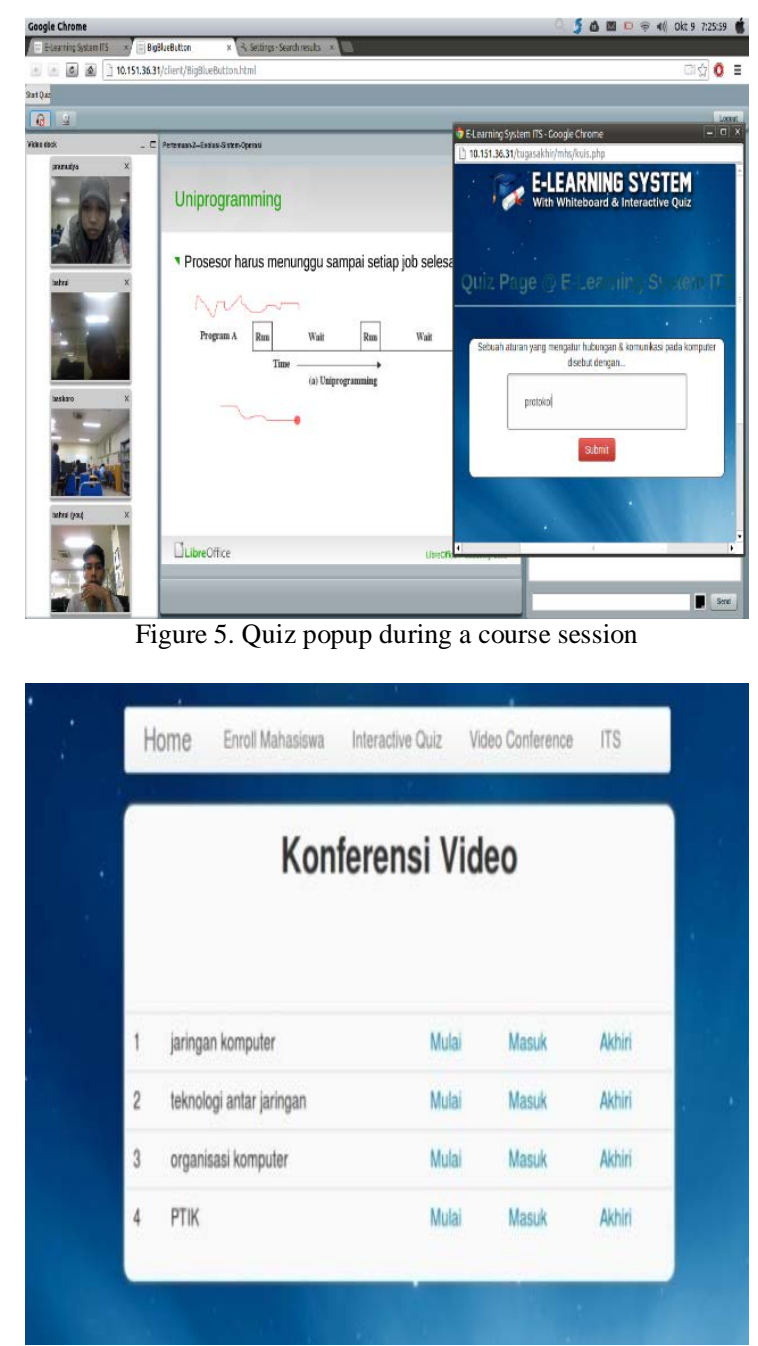

Figure 6. List of available conferences

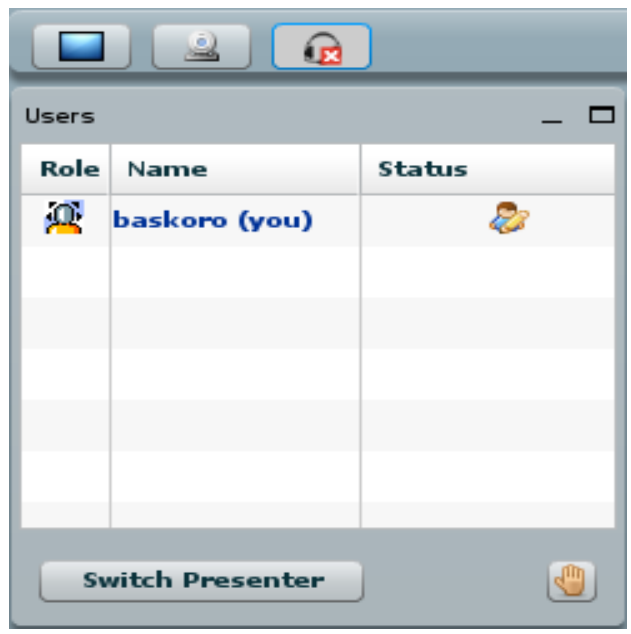

Figure 7. List of video conference sessions

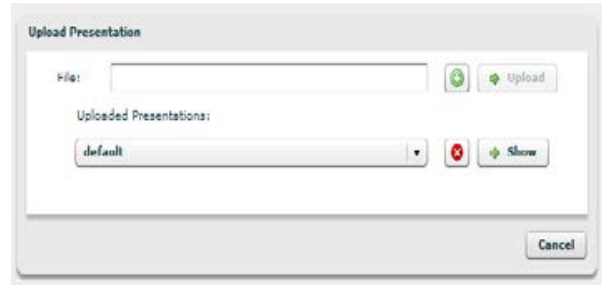

Figure 8. File selection to upload

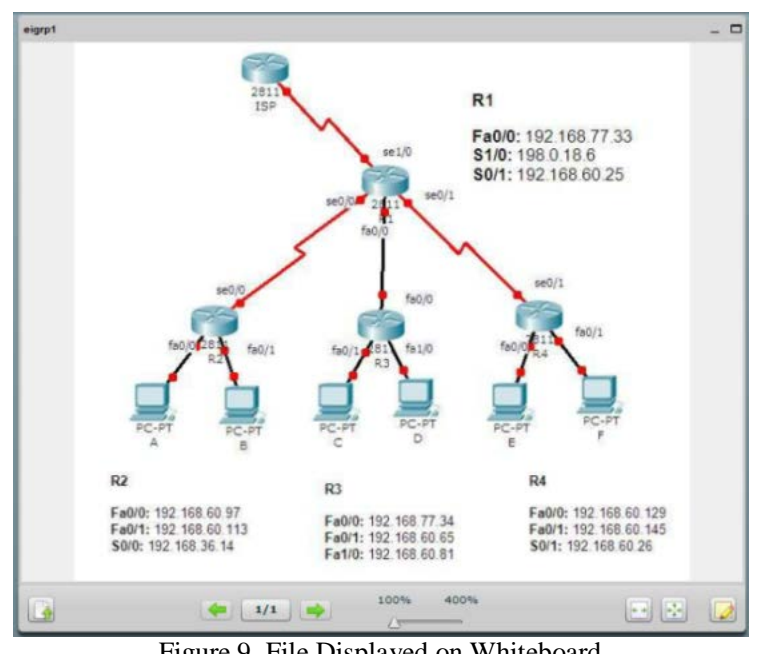

Figure 9. File Displayed on Whiteboard

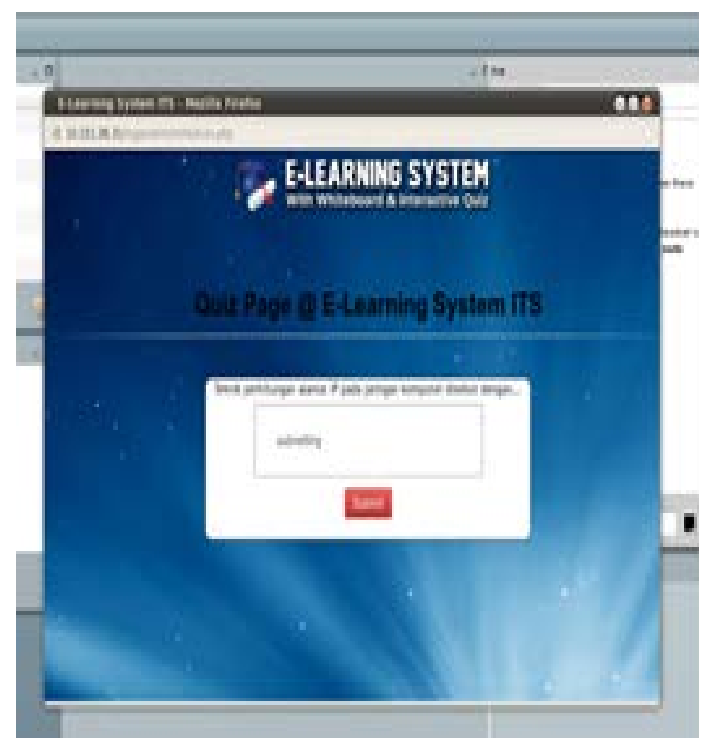

Figure 10. Working on Essay Quiz 


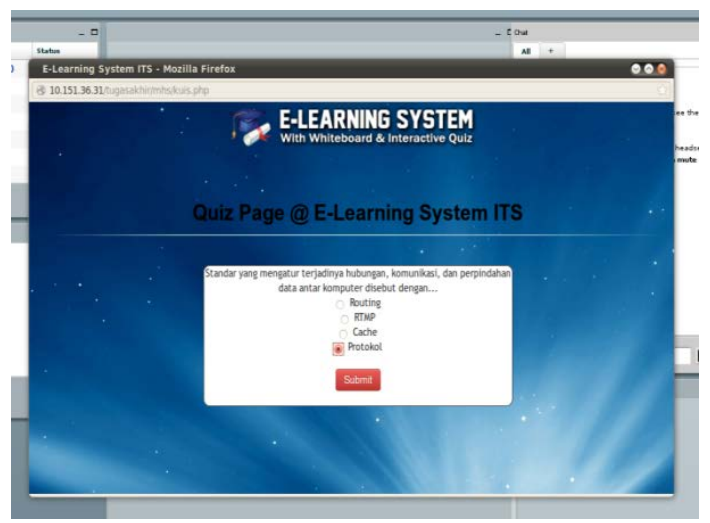

Figure 11. Working on Multiple Choice quiz

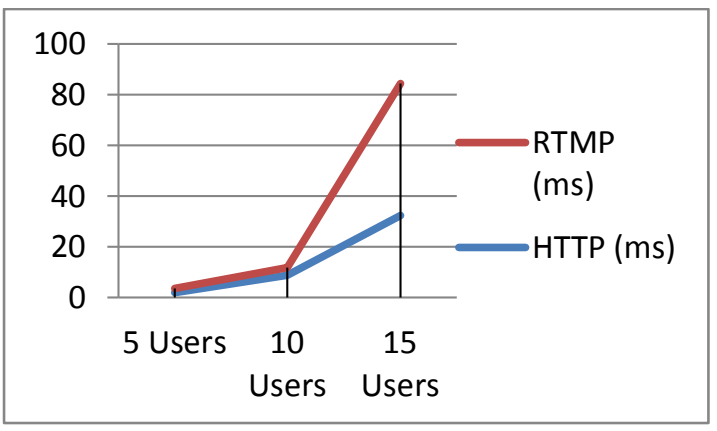

Figure 12. Comparison of Delay Value

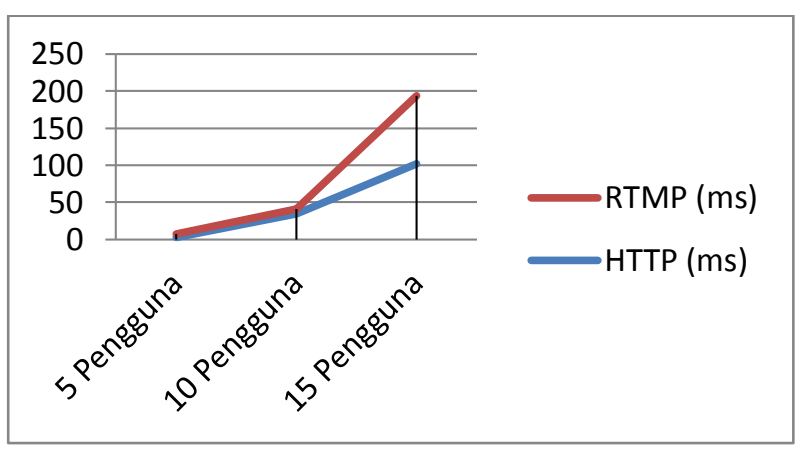

Figure 13 Comparison of Jitter Values

TABLE 1.

SOFTWARE SPECIFICATION

\begin{tabular}{cc}
\hline Server operating system & Ubuntu 10.04 \\
User operating system & $\begin{array}{c}\text { Microsoft Windows 7 32- } \\
\text { bit for user } \\
\text { Microsoft Windows 7 64- } \\
\text { bit for server }\end{array}$ \\
& \\
Server database & MySql \\
HTTP Server & NginX \\
Supporting framework & BigBlueButton \\
\hline \hline
\end{tabular}

TABLE 2.

HARDWARE SPECIFICATION

$\begin{array}{cc}\text { Server computer } & \text { Intel Core i3-2120 } \\ \text { 3.30GHz, RAM 4.00 GB }\end{array}$

User computer Intel Core 2 Duo E4500 2.20GHz, RAM 2.00

GB
TABLE 3.

5 USE CASE OF INTERACTIVE QUIZ ACTIVITY

\begin{tabular}{cc}
\hline ID & UJ-05 \\
Use case \\
reference \\
Name & UC-006 \\
Goal & Interactive Quiz Activity \\
Starting point & In the short answer quiz, students must fill in the \\
& answers in the text box, while in a multiple-choice \\
& quiz, students only \\
Scenario 1 & select the radio button for answering \\
Input & Student press the "submit" button \\
Output & Student answer \\
Experiment & Student answer is stored in the database \\
result & Succeeded \\
\hline \hline
\end{tabular}

TABLE 4.

RESULTS OF FUNCTIONAL TESTING

\begin{tabular}{lllll}
\hline \hline No.. & ID Use Case & ID Test & Result & Note \\
\hline 1 & UC-001 & UJ-02 & Succeed & - \\
2 & UC-002 & UJ-01 & Succeed & - \\
3 & UC-003 & UJ-0 2 & Succeed & - \\
4 & UC-004 & UJ-0 1 & Succeed & - \\
5 & UC-00 5 & UJ-01 & Succeed & - \\
\hline
\end{tabular}

TABLE 5.

DELAY CATEGORY

\begin{tabular}{cc}
\hline Category & Delay Time \\
\hline Very Good & $<150 \mathrm{~ms}$ \\
Good & $150 \mathrm{~s}$. D. $300 \mathrm{~ms}$ \\
Less & $300 \mathrm{~s}$. D. $450 \mathrm{~ms}$ \\
Very Less & $>450 \mathrm{~ms}$ \\
\hline \multicolumn{2}{c}{ TABLE 6. } \\
JITTER CATEGORY \\
\hline \hline Jitter Category & Number of Jitter \\
\hline Very good & $0 \mathrm{~ms}$ \\
Good & $0 \mathrm{~s} / \mathrm{d} 75 \mathrm{~ms}$ \\
Less & $76 \mathrm{~s} / \mathrm{d} 125 \mathrm{~ms}$ \\
Very Less & $125 \mathrm{~s} / \mathrm{d} 225 \mathrm{~ms}$ \\
\hline \hline
\end{tabular}

TABLE 7.

RESULT OF USER SURVEY

\begin{tabular}{cc}
\hline Aspects of Assessment & Value \\
\hline Ease of use features & 4.6
\end{tabular}

Color display and layout

The completeness of the features in the learning $\quad 4.0$ process

Web page access speed

The image quality of video conferencing

Whiteboard display quality

Delay video conferencing 